\title{
Design of Super Program-Controlling Thermostatic Device
}

\author{
http://dx.doi.org/10.3991/ijoe.v9iS7.3192 \\ Liu Li-xiu, He Ai-jiang, Li Xiang-biao \\ Yibin Vocational \& Technical College, Yibin, China
}

\begin{abstract}
Super thermostatic device was designed, using electric heating jacket as the heating element, silicon controlled voltage regulator as the actuator, program temperature controller as the controller. Orthogonal experiment was carried out to investigate the influencing factors on temperature control error, such as the heating medium, heating power, stirring speed and target temperature. The experimental results indicated that heating power and stirring speed have significant influence on temperature control error; and under the optimal conditions, the designed thermostatic device has thermostat control precision, $\pm 0.2 \square$, and temperature control accuracy, $0.3 \square$, which showed that the thermostatic device is a super thermostatic device with program control function..
\end{abstract}

Index Terms-program control, super thermostatic device, design.

\section{INTRODUCTION}

Super-thermostatic device is a kind of high-accuracy thermostatic equipment that is widely used in a lot of scientific research and production fields such as bioengineering, medicine, food, chemical engineering, metallurgy, petroleum and so on[1,2]. In order to make the media heated get well-distributed, other kind of media are required to be as the heat carriers normally. They are divided into water bath(within $100^{\circ} \mathrm{C}$ ), oil bath (100$\left.260^{\circ} \mathrm{C}\right)$, salt bath $\left(200-500^{\circ} \mathrm{C}\right)$, sand bath $\left(400-600^{\circ} \mathrm{C}\right)$ and lead bath $\left(350-1740^{\circ} \mathrm{C}\right)$ according to the difference of heat barriers and temperature range[3].

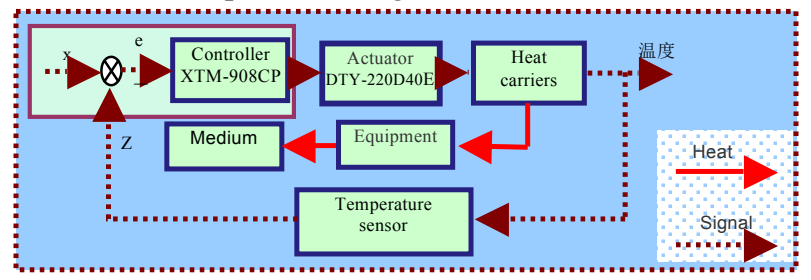

Figure 1. schematic diagram of heat carrier temperature control system

Thermostatic waterbath and thermostatic oil bath are the methods that are used the most extensively. See figure 1 for temperature control principle. And the temperature measures feed the temperature signals $(\mathrm{z})$ of heat carriers into controller, and the error $(\mathrm{e}=\mathrm{x}-\mathrm{z})$ is received by the comparison with the given value. $0 \sim 5 \mathrm{~V}$ signal voltage is output by the controller according to the error (e) through calculation. Final actuator (DTY-220D40E) is used to adjust the power of heater element according to the voltage strength. Thereby, temperature control is realized by adjusting its power, through which a temperature control system is constituted [4].

It can be seen from figure 1 that manipulated variable is the temperature of heat carriers. And heat carriers need to deliver the heat to the heated media through container. Therefore, the temperature of heated media is inferior to the temperature of heat carriers. In practice, what needs to be set is the temperature of heated media. Normally, the temperature of heat carriers needs to be increased higher a little bit so that the temperature of heated media can be guaranteed. Thus, the accuracy of temperature control is not high enough.

In this paper, it's drafted to cancel the heat carriers, and the electric jacket is used as the heating element and placed on the magnetic stirrer. And a flask is placed inside the electric jacket, while the programming temperature controller which has PID function is used as the controller, and realizes the high-accuracy programming temperature control below 350 $\square$. An orthogonal experiment is conducted over the main parameters which have an influence on the temperature control performance to analyze the influencing factors. Afterwards, the optimum parameters are adopted to have thermostatic performance and programming temperature control performance tests.

\section{MATERIAL AND INSTRUMENT}

\section{A. Instrument and equipment}

Silicon controlled voltage regulator (DTY-220D40E), XTM908P programming temperature controller, J2361 teaching resistance box, 360 ohmic resistance, KJ9250 multimeter, KX78-1 magnetic heating stirrer, 250ml flask, RS-485 convertor (USB connector), Pt100 thermal resistance.

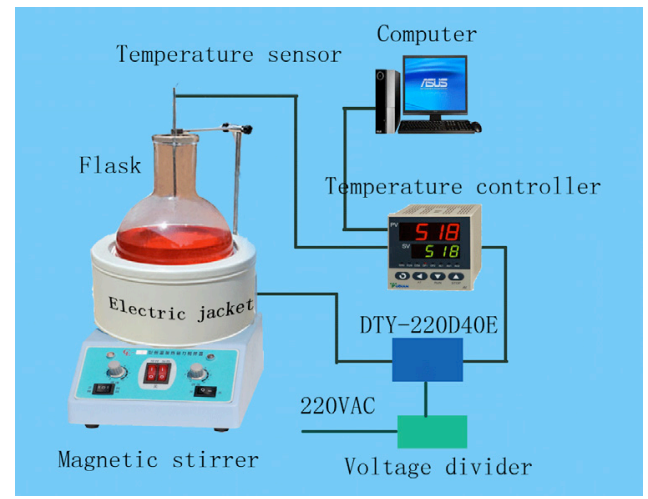

Figure 2. Super program-controlling thermostatic device 


\section{Design of Super Program-Controlling Thermostatic Device}

The power of ZHQ heating jacket is $300 \mathrm{~W}$, which is magnetic flat electric jacket, and mainly placed on the magnetic stirrer to carry on stirring and heating experiment. There is no insulating layer on the bottom of electric jacket, where there is a hole whose diameter is 60 $120 \mathrm{~mm}$ in the middle that it's convenient for the magnetic force to pierce through.

According to the controller and pressure regulating modules selected, the new control system constituted is as shown in figure 2.

\section{B. Material and software}

The freeware of microcomputer management software of meter is compiled by Yuyao Tempermeter Factory. Paraffinic oil is analytically pure.

\section{3 EXPERIMENTAL DESIGN}

\section{A. Principle of constant temperature}

For the thermal balance analysis of thermostatic device, here is the heat balance equation below:

$$
Q_{R}=Q_{T}+Q_{L}
$$

Thereinto: $\mathrm{Q}_{\mathrm{R}^{-}}$is the heat emitted from the electric jacket of thermostatic device, which can be expressed by heating power.

When the temperature of $\mathrm{Q}_{\mathrm{R}^{-}}$thermostatic device changes, heat absorbed or emitted is in direct proportion to the heated media and temperature change.

When $\mathrm{Q}_{\mathrm{L}}$ - loses its heat, the temperature is higher, the range of temperature is bigger, and the quantity of heat emitted to the environment is larger. This is related to the temperature, range of temperature and air humidity.

It can be seen from heat balance equation that when $\mathrm{Q}_{\mathrm{R}}=\mathrm{Q}_{\mathrm{L}}$, and $\mathrm{Q}_{\mathrm{T}}$ is zero, it means a constant bath temperature is realized. The main function of thermostatic waterbath controller is to change the power of heating elements so as to make up for the heat lost from water bath to the environment, and then to maintain at a stable temperature[5].

\section{B. 3.2 Experiment procedure}

A certain quantity of heating media paraffinic oil is added to the flask, and the rate of magnetic stirrer is adjusted. The thermometric element is immersed into paraffinic oil, and resistance box is used to have alternating voltage adjustment and to start temperature controller and set the temperature. RS-485 convertor connects the temperature controller to the USB interface of computer. After this, the microcomputer management software on the instrument is started to have data collection.

\section{3.2 Computing method}

After the bath temperature is stable, average value $\left(\mathrm{T}_{\text {avg }}\right)$ and maximum value $\left(\mathrm{T}_{\max }\right)$ or minimum value $\left(\mathrm{T}_{\min }\right)$ are obtained through the data in $30 \mathrm{~min}$. Error $\left(\Delta \mathrm{T}=\mathrm{T}_{\max }-\right.$ $\mathrm{T}_{\mathrm{avg}}$ or $\left.\Delta \mathrm{T}=\mathrm{T}_{\mathrm{avg}}-\mathrm{T}_{\mathrm{min}}\right)$ is the error of temperature control. When the error is smaller, accuracy is higher.

\section{3.3 Experimental design}

It can be seen from heat balance equation (1) that the factors of heating power, quantity of heating media, setting temperature and stirring rate can cause the change of temperature control error. Therefore, here are 4 parameters used as the investigation factors. Each factor has 4 levels, and L16 $\left(4^{5}\right)$ orthogonal experiment is designed as table 1. 16 times of experimental data obtained are filled in table 2 in order [6].

TABLE I.

ORTHOGONAL EXPERIMENTAL SCHEME OF TEMPERATURE CONTROL ERROR

\begin{tabular}{|c|c|c|c|c|}
\hline \multirow{2}{*}{$\begin{array}{c}\text { Factor } \\
\text { Level }\end{array}$} & A & B & $\mathrm{C}$ & D \\
\hline & $\begin{array}{c}\text { stirring rate, } \\
\mathrm{r} / \mathrm{min}\end{array}$ & $\begin{array}{c}\text { Heating } \\
\text { media,ml }\end{array}$ & $\begin{array}{c}\text { control } \\
\text { temperature, }\end{array}$ & $\begin{array}{c}\text { heating } \\
\text { power, } \%\end{array}$ \\
\hline 1 & 0 & 80 & 90 & 100 \\
\hline 2 & 50 & 120 & 120 & 80 \\
\hline 3 & 100 & 160 & 150 & 60 \\
\hline 4 & 150 & 200 & 180 & 40 \\
\hline
\end{tabular}

Remarks: voltage used stands for heating power, $80 \%$ heating power means $80 \%$ voltage (for example: $220 \times 80 \%=176 \mathrm{~V})$. Paraffinic oil serves as the heating medium.

TABLE II.

ORTHOGONAL EXPERIMENTAL RESULT OF TEMPERATURE CONTROL ERROR

\begin{tabular}{|c|c|c|c|}
\hline $\begin{array}{c}\text { Experiment } \\
\text { No. }\end{array}$ & $\begin{array}{c}\text { Temperature } \\
\text { difference }\end{array}$ & $\begin{array}{c}\text { Experiment } \\
\text { No. }\end{array}$ & $\begin{array}{c}\text { Temperature } \\
\text { difference }\end{array}$ \\
\hline 1 & 0.45 & 9 & 0.28 \\
\hline 2 & 0.3 & 10 & 0.28 \\
\hline 3 & 0.25 & 11 & 0.16 \\
\hline 4 & 0.22 & 12 & 0.16 \\
\hline 5 & 0.26 & 13 & 0.21 \\
\hline 6 & 0.28 & 14 & 0.27 \\
\hline 7 & 0.26 & 15 & 0.31 \\
\hline 8 & 0.33 & 16 & 0.25 \\
\hline
\end{tabular}

\section{RESULT DISCUSSION}

\section{A. Factor analysis of temperature control deviation}

SPSS18 is used to have univariate analysis of general linear model on the data of table 3 . See the analysis result as table 3 .

TABLE III. IMPACT ANALYSIS OF VARIOUS FACTORS ON TEMPERATURE CONTROL ERROR

\begin{tabular}{|l|l|l|l|l|c|}
\hline Source & $\begin{array}{c}\text { III quadratic } \\
\text { sum }\end{array}$ & df & $\begin{array}{c}\text { mean } \\
\text { square }\end{array}$ & F & Sig \\
\hline Stirring rate & 0.016 & 3 & 0.005 & 5.695 & 0.093 \\
\hline Heated media & 0.010 & 3 & 0.003 & 3.673 & 0.157 \\
\hline $\begin{array}{l}\text { Setting } \\
\text { temperature }\end{array}$ & 0.005 & 3 & 0.002 & 1.813 & 0.319 \\
\hline Heating power & 0.036 & 3 & 0.012 & 13.08 & 0.031 \\
\hline Total & 1.210 & 16 & & & \\
\hline Total revised & 0.070 & 15 & & & \\
\hline
\end{tabular}

It can be seen from table 3 that the error influence on temperature control: influence on heating power is highly significant $(\operatorname{Sig} \leq 0.05)$, influence on stirring rate is significant $(0.05<\operatorname{Sig} \leq 0.10)$, and the influence on heat- 
carrying capacity and setting temperature is not significant $(\operatorname{Sig}>0.1)$.

\section{B. Influence of stirring rate on temperature control error}

Stirring can help get rid of the problem of asymmetric temperature distribution to the heated media. It can be seen from figure 3 that the distribution of the temperature of paraffinic oil is more uniform as the increase of stirring rate. The error of temperature control becomes smaller gradually, and the temperature control accuracy is improved significantly. However, when the stirring rate is over $100 \mathrm{r} / \mathrm{min}$, it is easier to stir the paraffinic oil like a vortex, and the accuracy of measuring will be influenced. Thereby, the error of temperature control resulted will be higher. Therefore, the optimal stirring rate is $100 \mathrm{r} / \mathrm{min}$.

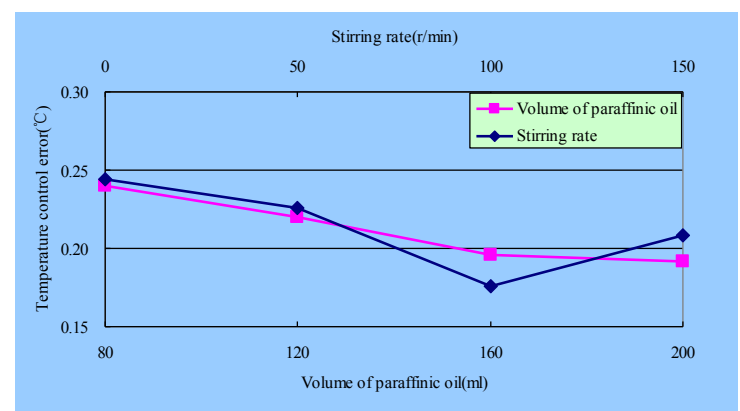

Figure 3. Influence of stirring rate and volume of paraffinic oil on temperature control error

\section{Influence of paraffinic oil volume on temperature control error}

It can be seen from the paraffinic oil curve of heated media in figure 3 . The error of temperature control decreases with the increase of paraffinic oil volume. In the formula (1), $\mathrm{Q}_{\mathrm{T}}$ is the heat absorbed or emitted by paraffinic oil because of the change of temperature. In the period without phase change, it can be expressed as $\mathrm{Q}_{\mathrm{T}}=\mathrm{q} \times \mathrm{C} \times \triangle \mathrm{t}$. $\mathrm{q}$ is the volume of paraffinic oil, $\mathrm{C}$ is the specific heat volume which is similar to a constant. $\triangle \mathrm{t}$ is the temperature change value of paraffinic oil. Suppose that $\mathrm{Q}_{\mathrm{T}}$ is invariant, the volume of paraffinic oil $\mathrm{q}$ rises, and the temperature change value of paraffinic oil $\triangle \mathrm{t}$ decreases, which means the error of temperature control decreases. In practice, if the volume of paraffinic oil is too large, temperature control will be sluggish.

\section{Influence of heating power on temperature control error}

It can be seen from figure 4 that the error of temperature control decreases and then increases as the heating power increasing gradually. The corresponding heating power is $60 \%$ when the error of temperature control is at the minimum.

For the purpose of a constant temperature control, when the heat balance equation is $\mathrm{Q}_{\mathrm{T}}=0$, so $\mathrm{Q}_{\mathrm{R}}=\mathrm{Q}_{\mathrm{L}}$, that's to say, the heat emitted by electric jacket is equal to the lost quantity of heat of paraffinic oil. Besides, $Q_{R}=U^{2} t / R$, and the electric heating power is in direct proportion to the square of voltage. If the voltage is oversize, heat emitted $\mathrm{Q}_{\mathrm{T}}$ increases, which causes $\mathrm{Q}_{\mathrm{T}}>0$. When the heat is undersize, $\mathrm{Q}_{\mathrm{T}}<0$. Whether the voltage is oversize or undersize, there will be temperature fluctuation, and the error of temperature control will be bigger.

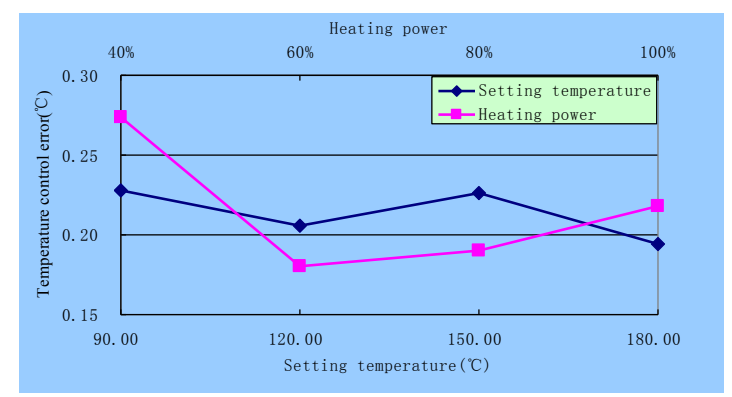

Figure 4. Influence of setting temperature and heating power on temperature control error

\section{E. Influence of setting temperature on temperature control error}

It can be seen from figure 4 that the regularity of the influence of setting temperature on temperature control error is not significant. On the contrary, it's small relatively. The influence of setting temperature on temperature control error is mainly embodied on heat loss $\left(Q_{L}\right)$. there is temperature difference $\triangle \mathrm{T}$ between setting temperature and room temperature. When the temperature difference increases, heat loss increases at the same time. In addition to setting temperature and room temperature, air humidity and fluidity can also have influence on heat loss, which thereby results in the change of temperature control error.

\section{RESULT VERIFICATION}

\section{A. 5.1 Constant temperature control}

Under the circumstance that the heating power is $60 \%$, stirring rate is $100 \mathrm{r} / \mathrm{min}$ and the volume of paraffinic oil is $160 \mathrm{ml}$, after the temperature is set at $80^{\circ} \mathrm{C}$ and $150^{\circ} \mathrm{C}$, and the XTM908P controller is adjusted and optimized, a constant temperature performance test will be conducted, and the curve will be reached as figure 5 .

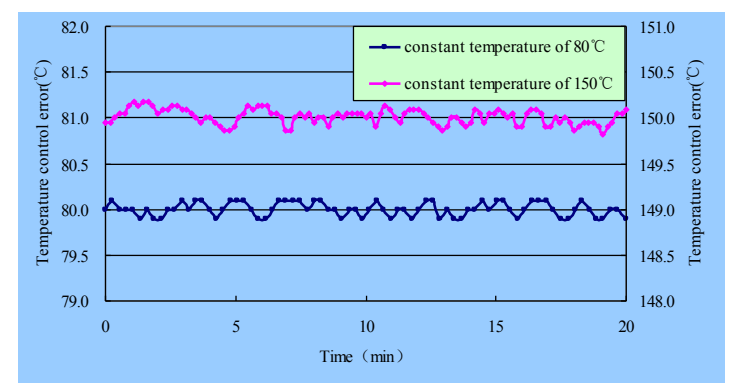

Figure 5. Curve of constant temperature performance test

In the constant temperature test when it is at $80^{\circ} \mathrm{C}$, the maximum value of temperature control error is $0.11^{\circ} \mathrm{C}$, and the relative error is $0.14 \%$. Besides, the curve is smoother. In the constant temperature test where it is 150 ${ }^{\circ} \mathrm{C}$, the maximum value of temperature control error is $0.15^{\circ} \mathrm{C}$, and the relative error is $0.10 \%$. Besides, the temperature fluctuation is significant. When the temperature rises, the maximum temperature control error increases a little bit, and the relative error decreases slightly as well. However, the maximum temperature 
control error is less than $0.20^{\circ} \mathrm{C}$ under both temperatures that the temperature control accuracy is very high.

\section{B. 5.2 Program temperature control}

The program temperature control performance test is conducted under the condition that when heat power is $60 \%$, stirring rate is $100 \mathrm{r} / \mathrm{min}$ and the volume of paraffinic oil is $160 \mathrm{ml}$. The program temperature control line $\mathrm{A}$ is set as: the temperature rises at the rate of $10^{\circ} \mathrm{C} / \mathrm{min}$ from $80^{\circ} \mathrm{C}$ to $140^{\circ} \mathrm{C}$ at a constant temperature for $15 \mathrm{~min}$. After this, the temperature drops to $120^{\circ} \mathrm{C}$ at the rate of $1.5^{\circ} \mathrm{C}$ $/ \mathrm{min}$. The electric jacket is shut down and drops in a natural rate. The program temperature control line $\mathrm{B}$ is set as: the temperature rises at the rate of $5^{\circ} \mathrm{C} / \mathrm{min}$ from $80^{\circ} \mathrm{C}$ to $120^{\circ} \mathrm{C}$ at a constant temperature for $20 \mathrm{~min}$. And then it rises to $160{ }^{\circ} \mathrm{C}$ at a maximum speed for a constant temperature. A curve of program temperature control performance test is drawn as figure 6 .

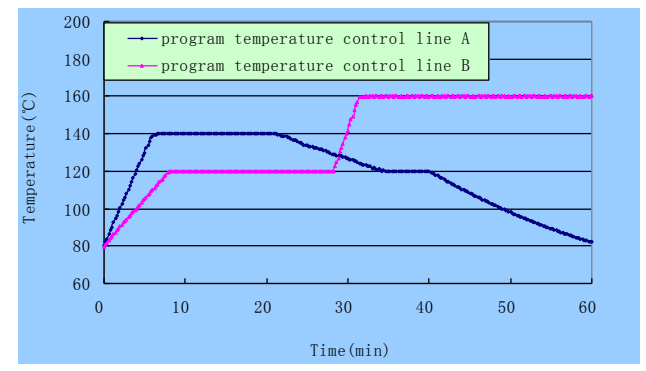

Figure 6. Curve of program temperature control performance test

It can be found after these two program temperature control lines and ideal temperature control lines are compared that the maximum temperature error is $0.14^{\circ} \mathrm{C}$ in each constant temperature stage of program temperature control line A. And the maximum temperature control error rises substantially in the stage of temperature rise, which is $0.26^{\circ} \mathrm{C}$. The natural rate of temperature fall is 2.6 ${ }^{\circ} \mathrm{C} / \mathrm{min}$ after electric heating jacket is shut down. This is the maximum cooling rate, which is related to the factors of such as heat preservation and room temperature of device. The maximum temperature control error in the constant temperature control of program temperature control line $\mathrm{B}$ is $0.16^{\circ} \mathrm{C}$, and the maximum temperature control error is $0.28^{\circ} \mathrm{C}$ in the stage of temperature rise. The maximum rate of temperature rise is $12.4^{\circ} \mathrm{C} / \mathrm{min}$, which is mainly related to the heating power of electric jacket.

\section{CONCLUSION}

\section{A. Influencing factors on temperature control error}

It is verified after the orthogonal experiment that the influence of stirring rate and heating power on temperature control error is more significant. Vortex can be easily resulted when the stirring rate is too slow, media are heated unevenly, and stirring rate is too fast, which can result in the increase of temperature control error. The heating power of electric jacket should be integrated with thermostatic device, and the heating voltage that is $60 \%$ is optimal. At this moment, the temperature control error is the least.

\section{B. Temperature control performance}

It is shown from constant temperature test that the performance of electric heating thermostatic device is excellent, the maximum temperature control error is less than $0.2^{\circ} \mathrm{C}$, and the relative error is less than $0.15 \%$.

It is shown from temperature programming test that the maximum rate of temperature increase is $12.4^{\circ} \mathrm{C} / \mathrm{min}$, and the maximum cooling rate is $2.6^{\circ} \mathrm{C} / \mathrm{min}$. The former one can be revised through the power of electric jacket, and the latter one is related to the factors such as heat preservation and room temperature, etc. The maximum rate of temperature increase and cooling rate can be on temperature control programming. The maximum temperature error is $0.28^{\circ} \mathrm{C}$, which shows its temperature control is excellent.

\section{Practical applicability}

It is cheaper to develop super program thermostatic device, and the equipment cost is less than 1000RMB. There are various specifications to electric jackets, which can meet the demand of scientific research production in different scales. Besides, the temperature control error is small, and the accuracy is high, which is an economical and practical super program control electric heating thermostatic device.

\section{SUGGESTION}

Since the measuring element Pt100 and program temperature controller selected are industrial instruments, they will influence the accuracy of thermostatic device. Therefore, it is feasible to choose the instrument whose accuracy is high to make improvement[15].

\section{REFERENCES}

[1] H.Schwenk, "Temperature control for a constant-temperature water bath," J. Phys. colloid Chem. 25(4): 761-763, 1948. http://dx.doi.org/10.1021/j150460a011

[2] A.Darbre and L.Speirsr, "Constant Temperature Water-Bath," Nature, 181(32): 264-265, 1958.

[3] H.T.Yang and T.F.Wu, "Lead hardening temperature measuring and control system for steel wire base on fuzzy PID," Coal Science and Technology, 35(2):33-37, 2007.

[4] A.J.He and L.X.Liu, "Reformation of Muffle Furnace' s Temperature Control System," Laboratory Research and Exploration, 30(10):204-206, 2011.

[5] D.M..Himmelblau and B.R.James, "Basic Principles and Calculations in Chemical Engineering," Upper Saddle River: Prentice Hall,2012, pp.258-286.

[6] L.Kirkup, "Experimental Methods: An Introduction To The Analysis And Presentation Of Data," Wiley,1996, , pp.113-118.

[7] Y.C. Mei

[8] Mei Yuchun, "Selection and Precision Analysis for thermal Energy Engineering Instrument," Journal of Nanjing Forestry University(natural sciences ), 1997,21(3):55-58.

\section{AUTHOR}

Liu Li-xiu received her master's degree in Environment Engineering from the Sichuan University, China, in 2006. engaged in teaching and scientific research of environment engineering and organic synthesis. (email:scu2000@gmail.com)

Submitted 16 September 2013. Published as re-submitted by the authors 22 October 2013. 